\title{
The photopic negative response (PhNR): measurement approaches and utility in glaucoma
}

\author{
Matteo Prencipe (iD - Tommaso Perossini • Giampaolo Brancoli • \\ Mario Perossini (1)
}

Received: 30 March 2020/ Accepted: 17 July 2020/Published online: 31 July 2020

(C) The Author(s) 2020

\begin{abstract}
Purpose Visual electrophysiological testing continues to generate interest among glaucoma experts because of its potential help in clarifying disease pathophysiology and promoting early detection of glaucomatous damage. The photopic negative response $(\mathrm{PhNR})$ is a slow negative component of the full-field electroretinogram that has been shown to provide specific information about retinal ganglion cells (RGCs) activity. The purpose of this article is to review the literature to explore the currently available measurement methods and the utility of $\mathrm{PhNR}$ in glaucoma diagnostic process.

Methods We gathered publications related to the origins, types of stimuli used, measurements methods and applications of the PhNR of ERG in animal models and humans through a search of the literature cited in PubMed. Search terms were: "PhNR", "photopic negative response", "glaucoma", "glaucomatous optic neuropathy", "ERG", "electroretinogram".
\end{abstract}

Results The most reliable PhNR measurements are obtained using a red stimulus on a blue background,

M. Prencipe ( $\square)$

Department of Surgical, Medical, Molecular Pathology and of Critical Area, University of Pisa, Pisa, Italy

e-mail: teopren@gmail.com

T. Perossini · G. Brancoli · M. Perossini

Studio Oculistico Associato Mario and Tommaso

Perossini, Livorno, Italy without requiring refractive correction, fixation monitoring, or ocular media transparency. Given its direct correlation with RGCs response, the PhNR measured as baseline-to-trough (BT) represents the most reliable parameter of evaluation. Glaucoma patients with evident perimetric defects show pathologic PhNR values. Even though the $\mathrm{PhNR}$ is promising in detecting early RGCs impairment, distinguishing between healthy subjects and suspect patients at risk of developing glaucomatous damage still remains challenging.

Conclusion The PhNR is a useful additional tool to explore disorders that affect the innermost retina, including glaucoma and other forms of optic neuropathy. In particular, comparing reports of the standard examinations (optic disc assessment, OCT RNFL measurement, standard automated perimetry) with the results of electrophysiological tests may be helpful in solving clinical diagnostic and management dilemmas. On the one hand, the PhNR of the ERG can examine the parvocellular pathways; on the other hand, the steady-state pattern ERG optimized for glaucoma screening (PERGLA) can explore the magnocellular pathways. This could give ophthalmologists a useful feedback to identify early RGCs alterations suggestive of glaucoma, stratify the risk and potentially monitor disease progression. 
Keywords PhNR - Photopic negative response · Retinal ganglion cell · Glaucoma $\cdot$ ERG . Electroretinogram

\section{Introduction}

Electroretinography is a minimally invasive diagnostic test that detects the electrical response of the retina to photic stimulation, which usually consists of a brief flash of light. Most often, electroretinograms (ERGs) are recorded using electrodes at the surface of the eye, which measures a summation of electrical activity of different retinal cells at corneal level [1].

The flashlight stimulates retinal photoreceptors at the beginning of the visual pathway, eliciting a biphasic waveform whose main components are represented by the a- and b-waves. Under scotopic conditions, the a-wave is a negative deflection generated mostly by the rods [2], while the following positive b-wave results from the electrical activity of depolarizing bipolar cells and the dependent bipolar $[\mathrm{K}+]$ currents that affect the Müller cells [3, 4] (Fig. 1a). In photopic conditions, when rod responses are saturated, the ERG reflects the complex interaction and activity of the cone circuits cells: the a-wave is generated by the cone photocurrents [5-7] with additional contributions from the hyperpolarizing cone bipolar cells and the horizontal cells [8]; on the other hand, the b-wave results from the combined activity of depolarization and hyperpolarization of the bipolar cells ("ON" and "OFF", respectively), horizontal cells and Müller cells [9] (Fig. 1b).

Conceptually, it was believed that the ERG trace merely represented the manifestation of the electric potentials of photoreceptors and bipolar cells, conveying these signals to the Müller cells, a supporting scaffold with extensions that cross the entire retina. However, it was noted later that the retinal ganglion cells (RGCs) contributed to the photopic (cone-driven) ERG in the form of a photopic negative response (PhNR) [10-12] (Fig. 1b). The PhNR is a slow negative component that follows the $b$-wave of the photopic ERG and represents the functional status of the inner layers of the retina (Fig. 2). More specifically, it originates in the RGC layer from the electrical activity of RGCs themselves and, given its slow timing, includes amacrine and glial cells mediation and contribution. Confirming this, intravitreal injection of tetrodotoxin in non-human primates inhibits the action potentials of RGCs and amacrine cells, subsequently reducing PhNR amplitude and prolonging implicit time [11, 13-15]. Therefore, considering that glaucoma occurs as a result of the degeneration of the RGCs and their axons, the PhNR may be helpful for the detection of early glaucomatous damage.

It is worth mentioning that, using long-lasting stimuli that dissociate the $\mathrm{ON}$ from the OFF response, a PhNR appears both after the b-wave (PhNR relative to the ON-pathways) and after the d-wave (PhNR relative to the OFF-pathways). Moreover, when employing this type of stimulation, a positive $\mathrm{i}$-wave after both b- and d-waves is observed. The i-wave recorded in the conventional short-flash ERG, which we usually observe before the PhNR, represents the combined activity of the ON- and OFF-bipolar cell pathways [16]. Nevertheless, the exact origin of i-waves has not been completely clarified. Rosolen et al. claimed a genesis from the innermost retinal layers [17], while other Authors indicated a more distal origin in the OFF-pathways [11, 14]. Interestingly, Horn et al. reported increased amplitudes of OFF i-waves in glaucomatous subjects [16], which was in agreement with previous findings by Viswanathan et al. in primary open-angle glaucoma patients [18], and by Rangaswamy et al. in glaucoma animal models [14]. Horn et al. also suggested that a reduction in PhNR amplitude could bring out the i-wave in glaucoma [16].

The purpose of this article is to review the different types of stimuli and measurements methods that may be used to assess the PhNR in a clinical setting, focusing on glaucomatous disease evaluation.

\section{Measuring the PhNR: types of light stimulation}

Among the different ERG waves, PhNR was first reported by Viswanathan et al., who used brief ( $\leq 5 \mathrm{~ms}$ ), long-duration $(200 \mathrm{~ms}$ ) red ganzfeld flashes on a rod-suppressing blue-adapting background [11]. After this first work, various types of stimulation and background conditions were tested.

Mortlock et al. [19] used white-on-white (W/W) stimulation. As expected, this resulted in a mass response of all cone photoreceptors [19, 20]. In contrast, monochromatic wavelength preferentially 


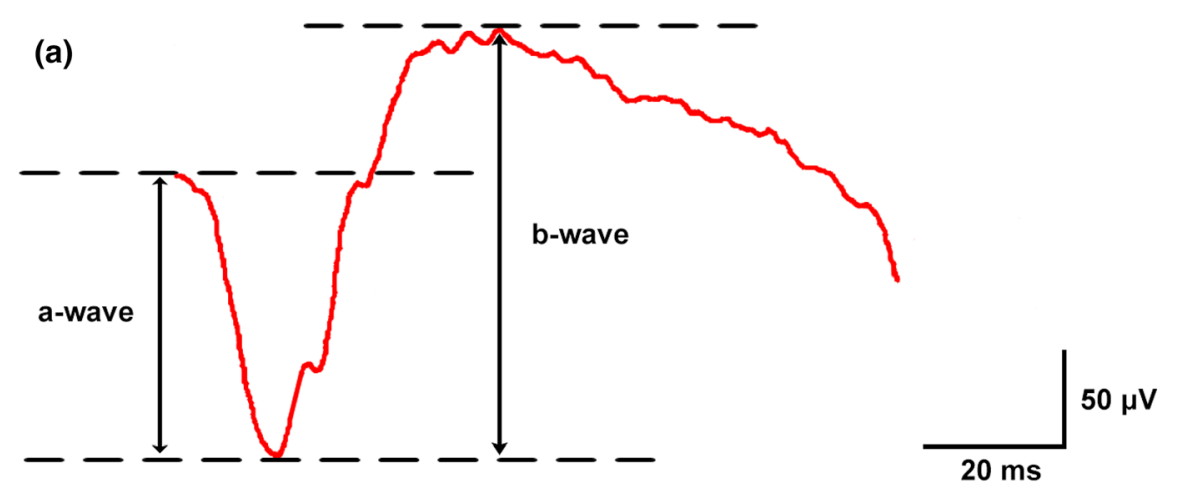

(b)

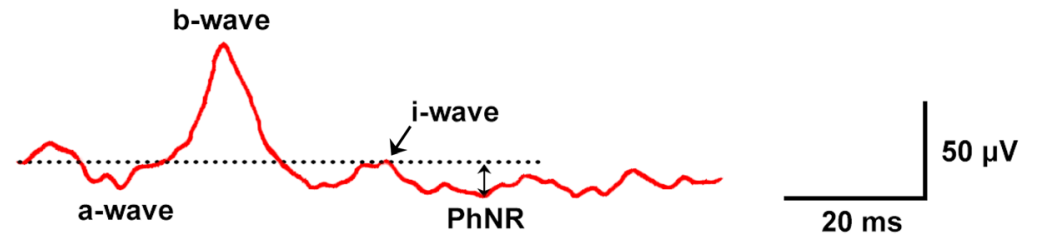

Fig. 1 Illustration of the dark- and light-adapted full-field electroretinogram (ERG) in a male subject. A standard flashlight elicits a mass electrical response of the entire retina. a Under scotopic conditions (white stimulus $10 \mathrm{~cd} \mathrm{~s} / \mathrm{m}^{2}$ ), the a-wave is a negative deflection generated mostly by the rods, while the following positive $b$-wave derives predominantly from Müller and ON-bipolar cells. b In photopic conditions (white flash
$3 \mathrm{~cd} \mathrm{~s} / \mathrm{m}^{2}$ on white background $30 \mathrm{~cd} / \mathrm{m}^{2}$ ), rods are saturated and the a-wave arises from cone photoreceptors and cone OFFbipolar cells, whereas the b-wave results from ON- and OFFcone bipolar cells. Although less evident with standard W/W stimulation, a positive $\mathrm{i}$-wave and a negative $\mathrm{PhNR}$ may also be noted

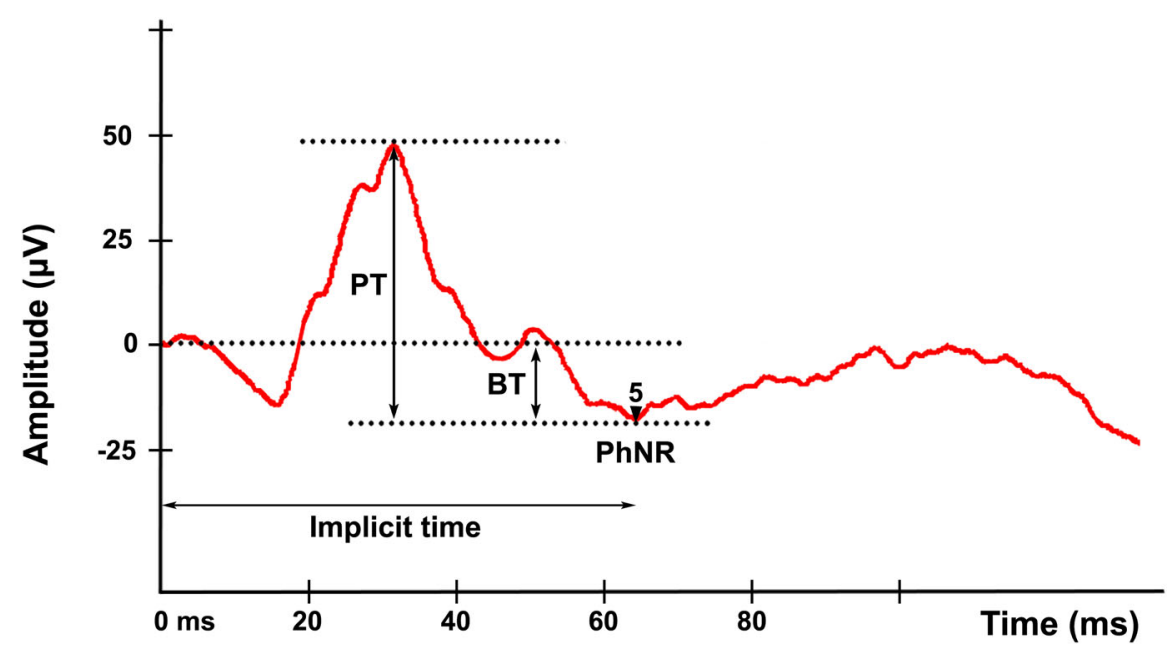

Fig. 2 Illustration of the photopic negative response (PhNR) of the ERG recorded following ISCEV guidelines (red light stimulus $<5 \mathrm{~ms}, 2.5 \mathrm{~cd} \mathrm{~s} / \mathrm{m}^{2}$ on blue background $10 \mathrm{~cd} / \mathrm{m}^{2}$ ) in a male subject. The photopic negative response ( $\mathrm{PhNR})$ is a slow negative component that follows the $b$-wave and represents the electrical activity of the retinal ganglion cell (RGC) layer. Figure shows PhNR amplitude measurements from baseline to PhNR trough (BT) and from b-wave peak to PhNR trough (PT). Implicit time refers to the interval between the stimulation and the peak of the negative wave 
stimulated a single subtype of cone cells, inducing less spectral antagonism in the receptive fields of ganglion cells $[20,21]$. Indeed, combinations of monochromatic stimuli (red $2.5 \mathrm{~cd} \mathrm{~s} / \mathrm{m}^{2}$ on blue $10 \mathrm{~cd} / \mathrm{m}^{2}$ ) probably minimize the centre-periphery antagonism of the receptive fields, thus resulting more effective in isolating the PhNR [20].

The spectral antagonism is due to the convergence of excitatory and inhibitory inputs from specific subtypes of cones. More specifically, the redON/green-OFF ganglion opposing cells receive both excitatory inputs from a long-wavelength-sensitive (L)-cone and inhibitory inputs from a medium-wavelength-sensitive (M)-cone, at the centre and periphery of the receptor field, respectively [22]. The signal that opposes L-cones to M-cones is transmitted through the population of midget ganglion cells, which are the most numerous [23], while the signal that opposes short-wavelength-sensitive (S)-cones to the LM-cones is transmitted through the bistratified ganglion cells, that are relatively few [22].

Since the S-cone cells present more permeable membranes [24] and higher metabolic demands, they are more sensitive to hypoxia and ischaemia [25, 26]. Thus, the S-cone (blue cone) PhNR of the ERG showed a high sensitivity in detecting glaucomatous damage [27, 28], similar to that provided by short wavelength automated perimetry (SWAP), which is a psycho-physical test that should detect visual field deficits 3-5 years before standard automated perimetry [29]. North et al. [30] hypothesized that the defect in the blue sensory mechanism could occur at a later stage of the glaucomatous disease, when the ganglion cell is no longer functioning. This was confirmed by the correlation found between SWAP and retinal nerve fiber layer (RNFL) thickness measured by optic coherence tomography (OCT) in glaucoma patients [30].

On the other hand, it is known that the PhNR tends to decrease with the shortening of stimulus wavelength, this being probably related to differential inductions of spectral antagonisms in the receptive fields of distinct RGC populations [21]. By eliciting the L-cones in an almost selective way [31], the red monochromatic stimulus predictably provides the greatest selective input to the centre or periphery of the receptive fields of the midget ganglion cells, as well as to the periphery of the bistratified ganglion cells, hence minimizing the spectral antagonism and resulting in better PhNR measurements. Indeed, the red flash stimulates the OFF-retinal pathways less efficiently, thus resulting in a lower b-wave when compared with a white stimulus, according to Rufiange et al. [32]. However, Rangaswamy et al. thought this could depend on the unequal summation of signals from the three subtypes of cones, with the b-wave amplitude resulting less affected by the red light stimulation than the white one [20].

In order to optimize clinical applications, the International Society for Clinical Electrophysiology of Vision (ISCEV) has recently provided a protocol for recording and analysing the $\mathrm{PhNR}$ in response to a brief flash. The ISCEV extended protocol advises, after pupil dilation and $10 \mathrm{~min}$ of photopic adaptation, to use short stimuli $(<5 \mathrm{~ms})$ of red light (630-660 nm, 1.0-2.5 phot $\mathrm{cd} \mathrm{s} / \mathrm{m}^{2}$ ) on a background saturated with blue $\left(450-485 \mathrm{~nm}, 10\right.$ phot $\left.\mathrm{cd} / \mathrm{m}^{2}\right)$ [33] (Fig. 2).

\section{Measuring the PhNR: different techniques}

Initially, there was a great variety of orientations in methodology to achieve the most accurate and reliable results in PhNR measurement.

In a study comparing open-angle glaucoma patients with healthy controls, Sustar et al. [21] decided to measure the PhNR from baseline to trough (BT) (Fig. 2). The Authors maintained the same blue background $\left(470 \mathrm{~nm}, 10 \mathrm{~cd} / \mathrm{m}^{2}\right)$ and used different stimulus wavelengths (i.e. red, amber, green and white), HK-loop electrodes (in contact with the sclera at the conjunctival fornix), and $10 \mathrm{~min}$ of photopic adaptation. The best performance was obtained using a $2.5 \mathrm{~cd} \mathrm{~s} / \mathrm{m}^{2}$ red stimulus $(635 \mathrm{~nm}, 4 \mathrm{~ms})$, while increasing the stimulus power (to $5 \mathrm{~cd} \mathrm{~s} / \mathrm{m}^{2}$ and $7.5 \mathrm{~cd} \mathrm{~s} / \mathrm{m}^{2}$, respectively) resulted in less reliable measurements due to glare artefacts. Moreover, a statistically significant difference in PhNR amplitude between healthy subjects and glaucoma patients was observed, regardless of using either a red or a white light stimulation. However, employing a red stimulus resulted more sensitive in terms of amplitude reduction $(-68 \%, p<0.001)$ when compared with a white stimulus $(-38 \%, p=0.001)$. Confirming this finding, the cutoff obtained with the red stimulus (i.e. $-16.2 \mu \mathrm{V}$ ) provided a $92.9 \%$ specificity and a $92 \%$ 
sensitivity, thus performing well in distinguishing between glaucomatous and healthy subjects.

In an effort to determine the most reliable technique for assessing the PhNR amplitude, Mortlock et al. [19] recorded ERGs in 31 healthy subjects (aged from 21 to 40 years) using both DTL electrodes and skin electrodes. The Authors used a $1.5 \mathrm{~cd} \mathrm{~s} / \mathrm{m}^{2}$ red stimulus on a continuous blue background of sufficient intensity to saturate S-cones and rods (3.9 log scot td), after preadapting the subjects to the background luminance for a minimum of $5 \mathrm{~min}$, and assuming a $7-\mathrm{mm}$ pupil dilation. The following amplitude measurement techniques were used:

- PT (Peak-to-Trough, i.e. the difference between the peak of b-wave and the PhNR trough) (Fig. 2);

- BT (Baseline-to-Trough, i.e. the difference between the pre-stimulus baseline and the PhNR depression) (Fig. 2);

- BF (Baseline-to-Fixed time-point, i.e. the amplitude measured from the baseline to a predetermined time-point);

- PF (Peak-to-Fixed time-point, i.e. the difference between the peak of b-wave and a set time-point);

- PTR (ratio b-wave/PhNR, i.e. the ratio between b-wave amplitude-measured from the depression of a-wave to the peak of b-wave-and PhNR amplitude measured as PT).

As a result, the amplitude of the PhNR measured as PT seemed to achieve a better inter-ocular and intersession repeatability (around $50 \%$ and $45 \%$ variability, respectively). Interestingly, they found PTR to provide the most repeatable results (around 25\% variability for skin and DTL electrodes), this being particularly useful when the b-wave shows a reduced amplitude response. On the other hand, PhNR measurement as BT was the poorest performing technique and should be avoided according to the Authors. In case a prominent i-wave was present after b-wave (in most cases at larger amplitudes), the PhNR trough was identified as the lowest point, which may precede or follow the i-wave. Subsequently, the implicit time (IT) was measured at this trough (mean value of $71.5 \mathrm{~ms}$ ). Therefore, in clinical terms, this study suggested that a longitudinal change in PTR value of more than $25 \%$ or an alteration of more than $45 \%$ in PT should be considered clinically significant, as well as any interocular difference in PTR of more than 25\%.
Viswanathan et al. found an increase in IT of about $8 \mathrm{~ms}$ when comparing a group of healthy elderly subjects (aged 71-80 years) with a group of younger controls (aged 21-30 years) [18]. In a subsequent work, Binns et al. [34] used the Naka-Rushton equation to evaluate the intensity-response ratio, measuring the PhNR both as PT and BT. This study identified PT as the best parameter for PhNR assessment in terms of variability [34].

It is worth noting that the neuronal alterations due to glaucoma affect the amplitude of the PhNR, leaving the implicit time relatively unchanged [18, 27, 35]. All components of the ERG tend to vary more in breadth than IT, and this also applies to the PhNR $[19,36]$. However, it is important to keep in mind that interindividual variations can be attributed to anatomical factors such as pigmentation of the fundus [37] and axial length [38, 39], or technical factors (e.g. electrodes position, impedance) [39], as well as intrinsic changes in retinal function.

Tang et al. [15] evaluated the reliability of the PhNR with the test-retest method in 49 healthy subjects (aged 21-72 years), choosing to investigate the right eye to decrease variability. After pupil dilation, signals were acquired using DTL electrodes, a pre-adaptation to background room light of at least $1 \mathrm{~min}$, and a brief pre-adaptation to blue background $\left(10 \mathrm{~cd} / \mathrm{m}^{2}\right)$ of approximately $1 \mathrm{~min}$ before delivering the first stimulus. This study followed the criteria previously adopted by Mortlock et al. [19], measuring $\mathrm{BT}, \mathrm{BF}$ and PT, but also considering the BT/b-wave ratio. As a result, the most reliable measurements were obtained with a red stimulus ( $4 \mathrm{~ms}, 1 \mathrm{~cd} \mathrm{~s} / \mathrm{m}^{2}$ ) and, in agreement with Mortlock et al.'s work [19], PT was demonstrated to be a reliable method in terms of repeatability. Furthermore, they found no statistical correlation between PhNR amplitude and age.

More recently, Van Alstine and Viswanathan explored the test-retest reliability of the multifocal PhNR (mfPhNR) using DTL electrodes [40]. They studied the right eye of 61 healthy subjects (aged 22-79 years) on two separate days. Based on previous mean IT measurements [19], the $\mathrm{mfPhNR}$ was recorded at a fixed time-point $(75 \mathrm{~ms})$ at the center of the macula considering a temporal interval of 15 ms. In agreement with Tang et al. [15], the Authors concluded that PT was the best performing measurement technique in terms of reproducibility when compared to $\mathrm{BT}, \mathrm{BT} / \mathrm{PT}$ ratio and $\mathrm{BT} / \mathrm{b}$-wave ratio. 
From a clinical point of view, since BT reflects RGCs activity and constitutes $30-50 \%$ of PT value, a reduction in PT of about 30-50\% was considered a suspicious sign of disease.

Joshi et al. [41] also used the Naka-Rushton equation, which allows a quantitative description of the intensity-response function, in order to evaluate the effect of age and test-retest reliability of the PhNR in 45 healthy subjects. ERG was recorded using DTL electrodes, red stimuli (duration $<5 \mathrm{~ms}$, intensity range $0.00625-6.4 \mathrm{~cd} \mathrm{~s} / \mathrm{m}^{2}$ ) on a constant blue background $\left(7 \mathrm{~cd} / \mathrm{m}^{2}\right)$. However, only data up to $1.6 \mathrm{~cd} \mathrm{~s} /$ $\mathrm{m}^{2}$ were used for the Naka-Rushton fit as a photopic hill phenomenon was observed not only in BT, PT and b-waves, but also in the PhNR [28, 34]. Therefore, they reported that none of the Naka-Rushton fit parameters were significantly affected by age for PT, BT or b-wave measurements. However, it has to be mentioned that BT measurements alone resulted in a weak but statistically significant correlation with age. With respect to test-retest reliability, the fit parameters for PT measurements performed better than those for BT. Previous studies $[15,19,39]$ found that the test-retest repeatability of the BT/PT ratio in healthy subjects was better than that obtained with BT alone. On the other hand, BT reflects RGCs response and should be more indicative for glaucoma than PT, which also includes the activity of unaffected or slightly compromised bipolar cells. Thus, since the b-wave is generated by bipolar cell activity and glaucoma selectively affects RGCs, the normalized $\mathrm{BT} / \mathrm{b}$-wave ratio should theoretically better detect glaucomatous alterations. Supporting this, Preiser et al. showed that the $\mathrm{BT} / \mathrm{b}$-wave ratio was more sensitive to glaucomatous damage than BT alone [42].

\section{Measuring the PhNR: clinical experiences}

PhNR amplitude has been found to be reduced in many pathological conditions including glaucomatous optic neuropathy [43], ocular hypertension [18, 30, 44, 45], Leber hereditary optic neuropathy [46], optic nerve atrophy [47], diabetic retinopathy [48], central retinal artery occlusion [49] and idiopathic endocranial hypertension [50, 51]. After having established that the red-on-blue $(\mathrm{R} / \mathrm{B})$ stimulation gives more discriminating results than white-on-white (W/W) stimulation in detecting glaucomatous damage [20, 21], we now present the most interesting experiences in the field.

In a prospective, cross-sectional study Banerjee et al. [52] compared 25 glaucoma patients with 50 agematched healthy controls, using Burian-Allen electrodes, $10 \mathrm{~min}$ of pre-adaptation to blue, white and yellow backgrounds $\left(10 \mathrm{~cd} / \mathrm{m}^{2}\right)$, and various stimulus intensities in a first phase. Then, they used the following settings as reference parameters: stimulus duration $<4 \mathrm{~ms}, 3.5 \mathrm{~cd} \mathrm{~s} / \mathrm{m}^{2}$ intensity for $\mathrm{R} / \mathrm{B}$ and W/W stimulations, $1 \mathrm{~cd} \mathrm{~s} / \mathrm{m}^{2}$ intensity for $\mathrm{B} / \mathrm{Y}$. When employing the R/B method, PhNR amplitude was found to be significantly reduced in glaucoma eyes $(27.11 \pm 14.88 \mu \mathrm{V})$, while IT was increased (77.98 $\pm 6.37 \mathrm{~ms})$. Receiver operating characteristic (ROC) curve was performed for all stimuli in order to analyse the area under the curve (AUC) and sensitivity-specificity. The ROC curve showed largest AUC in $\mathrm{R} / \mathrm{B}$ PhNR and also higher sensitivity and specificity ( $72 \%$ and $80 \%$, respectively). Interestingly, the specificity of red-on-blue PhNR was found to be better than that of RNFL thickness and slightly better than that of MD. Even though the amplitudes recorded in the B/Y ERG of glaucomatous patients were much higher in absolute value than in controls (even using very low intensities in this setting), the corresponding $\mathrm{B} / \mathrm{Y} \mathrm{PhNR}$ reduction was less pronounced than that obtained with R/B stimulation.

Cvenkel et al. [53] evaluated the discrimination ability of both PERG and PhNR in patients with ocular hypertension (OHT) and early glaucoma as well as in glaucoma suspects, comparing them with healthy controls. According to the Authors, PhNR amplitude measured from the baseline (BT) distinguished best between glaucoma and control groups and performed better than $\mathrm{PhNR} / \mathrm{b}$-wave ratio. Of note, in eyes with suspected glaucoma, decrease in PhNR amplitude was associated with small changes in peripapillary retinal and macular NFL thicknesses. However, PhNR showed a high sensitivity $(91.7 \%)$ for both glaucoma suspect and early glaucoma, but lower specificity (58.8\% and $70 \%$ in the two groups, respectively). In other words, approximately one-third of healthy subjects could be recorded as false positive.

Preiser et al. [42] examined PhNR and steady-state PERG from patients with pre-perimetric glaucoma (defined as the presence of pathological optic disc appearance and normal visual field) and glaucoma, comparing them with a control group. PhNR was 
recorded using a red stimulus $(5 \mathrm{~ms}, 635 \mathrm{~nm})$ on a blue background $\left(450 \mathrm{~nm}, 10 \mathrm{~cd} / \mathrm{m}^{2}\right.$ ), and varying the intensity from 0.1 to $4 \mathrm{~cd} \mathrm{~s} / \mathrm{m}^{2}$. Then, the PhNR amplitude from baseline to trough at $72 \mathrm{~ms}$ and the $\mathrm{PhNR} / \mathrm{b}$-wave ratio were measured. Both PhNR and PERG performed similarly to distinguish between healthy subjects and pre-perimetric patients. In particular, both $\mathrm{PhNR} / \mathrm{b}$-wave ratio and $0.8^{\circ} / 16^{\circ}$ ratio of steady-state PERG performed better than amplitudes. However, no correlation was found between the two ratios, while there was a correlation between the PhNR and the $0.8^{\circ}$ PERG. Since the PERG can be affected in eyes with pre-perimetric glaucoma [54-57], and the $\mathrm{PhNR}$ seems to be more closely related to perimetric defects [12], the corresponding ratio values might detect different disease mechanisms.

Niyadurupola et al. [58] evaluated glaucomatous patients in which the intraocular pressure (IOP) dropped by more than $25 \%$ compared to the baseline. This study found a correlation between IOP decrease, and both PhNR amplitude increase and $\mathrm{PhNR} / \mathrm{b}$-wave ratio. Signals were recorded using DTL electrodes and stimuli with intensities similar to those subsequently recommended by ISCEV [33] $\left(2.25\right.$ and $3 \mathrm{~cd} \mathrm{~s} / \mathrm{m}^{2}$, blue background of $20 \mathrm{~cd} / \mathrm{m}^{2}$ ). Using a brief red stimulus $\left(2.25 \mathrm{~cd} \mathrm{~s} / \mathrm{m}^{2}\right)$, the recorded PhNR was higher in healthy controls $(27 \pm 3.5 \mu \mathrm{V})$ when compared to OHT and glaucomatous patients $(18.5 \pm 2.8 \mu \mathrm{V}$ and $12.7 \pm 1.6 \mu \mathrm{V}$, respectively). Similarly, the PhNR/b-wave ratio also resulted higher in healthy subjects $(0.319 \pm 0.035)$ than OHT and glaucoma patients $(0.269 \pm 0.051 \quad$ and $0.134 \pm 0.016$, respectively). Using HK-loop electrodes and R/B method $\left(2.5 \mathrm{~cd} \mathrm{~s} / \mathrm{m}^{2}, 10 \mathrm{~cd} / \mathrm{m}^{2}\right)$, similar results to those found by Sustar et al. [21] were reported: the measured PhNR was $25.4 \pm 7.1 \mu \mathrm{V}$ and $8.3 \pm 5.8 \mu \mathrm{V}$ in healthy controls and glaucomatous patients, respectively.

With similar parameters (red stimulus of $2 \mathrm{~cd} \mathrm{~s} / \mathrm{m}^{2}$ on blue background of $25 \mathrm{~cd} / \mathrm{m}^{2}$ ), Shen et al. [45] reported different PhNR values, namely $47.8 \pm 10.7 \mu \mathrm{V}$ and $27.2 \pm 13.5 \mu \mathrm{V}$ in healthy controls and glaucoma patients, respectively. These results were close to those reported by Banerjee et al., who used a stronger stimulus $\left(3.5 \mathrm{~cd} \mathrm{~s} / \mathrm{m}^{2}\right)$ [52]. However, the Authors specified neither which type of corneal electrodes was used nor reported any IT measurement.
Machida et al. [59] used a red stimulus (3 ms, $644 \mathrm{~nm}, 1600 \mathrm{~cd} / \mathrm{m}^{2}$ ) on a blue background (470 nm, $40 \mathrm{~cd} / \mathrm{m}^{2}$ ) in open-angle glaucoma patients and healthy subjects. By analysing the PhNR amplitude (measured from baseline to trough at $\sim 70 \mathrm{~ms}$ ) and the $\mathrm{PhNR} / \mathrm{b}$-wave ratio, they found a significant correlation with RNFL thickness measured by OCT and optic disc topography (rim area, cup/disc area ratio) assessed by confocal scanning laser ophthalmoscopy. More specifically, the PhNR amplitude decreased together with the functional worsening of glaucoma (in terms of visual field defect), as well as the neural loss assessed by RNFL and optic nerve head morphology. Furthermore, differences between optic nerve atrophy (induced by trauma, compression and optic neuritis) and glaucomatous disease were investigated. In a previous work by Gotoh et al. [47], PhNR amplitude highly correlated with RNFL thickness, which showed diffuse and thus more easily detectable damage. On the other hand, this correlation was much lower in glaucomatous eyes because the localised RNFL impaired areas were more difficult to detect at early stage of disease. In agreement with Shen et al. [45] and considering that the PhNR is supposed to reflect the overall function of the RGCs throughout the entire retina, PhNR and RNFL measurement seemed more suitable for optic nerve pathology assessment. Indeed, in these cases RGCs are more widely impaired than in early or moderate stages of glaucoma, where RGCs are only regionally affected. Hence, in subsequent works, more attention was focused to focal techniques alone [12, 44, 60-63].

It is also worth mentioning Wilsey et al.'s study on non-human primate models of experimental glaucoma [64]. The Authors compared diagnostic performance and structure-function correlations of multifocal ERG (mfERG), full-field flash ERG (ffERG) PhNR and transient PERG. Based on previous evidence, the highfrequency component (HFC) of the slow-sequence of mfERG, the PhNR amplitude (measured as BT) of the red-on-blue ffERG and the N95 of the transient PERG were considered as the best parameters from each mode in terms of diagnostic efficacy and correlation to anatomic damage. It is important to note that these parameters represent three different expressions of RGCs activity, as the N2 from mfERG is comparable to the PhNR from ffERG, which shares in turn the same generators of the N95 from PERG [13, 65]. The findings confirmed the high sensitivity of PhNR and 
$\mathrm{PhNR} / \mathrm{b}$-wave ratio in detecting RGCs functional impairment, as well as the strong correlation with structural loss and the best overall diagnostic accuracy. The normalized HFC showed similar results, but the mfERG was shown to provide only modest diagnostic support in human glaucoma [57, 66-70]. On the other hand, the transient PERG showed the widest population variance and the poorest test-retest reliability, thus performing worse than the other two ERG modalities. However, it should be kept in mind that different ERG parameters might detect complementary diagnostic information. The Authors addressed this question by plotting the eyes flagged by each of the best performing ERG parameters under study in area-proportional Euler diagrams. Since some cases were detected only by one parameter ( $8 / 42$ by mfERG,5/42 by PhNR,1/42 by PERG), these results suggested that complementary information could be available through testing by multiple ERG modalities.

\section{Measuring the PhNR: pros and cons in clinical practice}

As an objective measure of global retinal function, ERG testing is a diagnostic tool with several potential applications in ophthalmology, even in pathologies that clinicians manage on a daily basis. However, its use is sometimes associated with niche disease entities and there is often a need to refer patients to a specialised centre for testing and interpretation. As a result, there may be a perception that the technique is impractical for routine clinical practice. From this point of view, the availability of office-based platforms including tabletop, cart-based and suitcasesized units might allow routine access to different types of electrophysiology testing and change the perceived clinical utility of ERG and PhNR. Moreover, the lack of a standardized technique for PhNR clinical testing has been recently addressed with the publication of the ISCEV-extended protocol [33].

Currently, the PERG is the most well-established ERG technique for glaucoma detection [71-75], and previous studies indicated that it may be most beneficial as an adjunct in the diagnosis and management of glaucoma suspects (with normal or borderline visual fields and/or RNFL thickness) by helping stratify the risk [76, 77]. However, careful control of steady central fixation, optimal refractive correction and clear ocular media are necessary. More importantly, as it depends on a cascade of intact outer retinal signals, the PERG alone is not a specific assay of RGC function and needs to be "confirmed" by a ffERG to specifically evaluate the macular cone and cone bipolar responses. On the other hand, the PhNR may be able to overcome these limitations, being potentially more feasible in a clinical setting. Even relying on a preserved feed-forward response of cone photoreceptor and cone bipolar cells as PERG, the PhNR gives an immediate way of assessing the outer retinal cells functional state, by simultaneously recording aand b-waves and without any other confirmation test. Furthermore, the PhNR should allow an early detection of functional abnormalities of all the RGCs including the most peripheral ones, whereas the PERG examines only the central RGCs, which are involved later in the development of manifest (or perimetric) glaucoma. This means that the PhNR amplitude may reveal alterations in eyes with a normal visual field, such as OHT or suspect glaucoma, while the N95 wave of PERG tends to decrease as the disease progresses affecting the ganglion cells within the central $30^{\circ}$ of the visual field. Furthermore, in addition to its independence of patient motor and cognitive skills (unlike standard automated perimetry), the PhNR does not require refractive correction, meticulous fixation monitoring or ocular media transparency (which is also important for reliable fundus photography and OCT acquisition).

A possible clinical disadvantage might be represented by the need for pupil dilation to improve PhNR measurement accuracy. However, since a comprehensive dilated eye examination should be performed routinely in almost any patient-and even more crucially in glaucoma suspects to correctly assess the optic nerve, the PhNR could be recorded at the end of the visit. This could allow clinicians to have an additional element supporting a diagnosis and guiding appropriate treatment decisions in uncertain cases such as glaucoma suspects or ocular hypertensive subjects.

\section{Conclusion}

The main points of this review are summarized in Table 1. The most reliable PhNR measurements are obtained using a red stimulus on a blue background. 
Table 1 Main points

The photopic negative response (PhNR) of the cone-driven ERG is a slow negative wave that follows the b-wave and originates from the innermost layers of the retina

The PhNR is an objective measure of retinal ganglion cells (RGCs) functional status and sensitive to glaucomatous alterations A monochromatic red stimulus on blue background (R/B) results more effective in isolating the $\mathrm{PhNR}$

The PhNR test does not require refractive correction, meticulous fixation monitoring or ocular media transparency

A reduced $\mathrm{PhNR}$ may play a potential role in early glaucoma detection, risk stratification and disease progression monitoring, especially when visual field testing and/or OCT measurement are inconclusive, not reliable, or difficult to perform

Considering its direct correlation with retinal ganglion cells response, the PhNR measured as baseline-totrough (BT) represents the most reliable parameter in representing RGCs activity. On the other hand, using a predetermined time-point for recording signals does not seem appropriate because of age-related implicit time (IT) variability.

It is well known that the current "gold standard" for glaucoma diagnosis and monitoring is a combination of stereoscopic assessment of the optic disc, evaluation of structural changes in the optic nerve detected by OCT and visual field tests. Nevertheless, it has been shown that glaucoma patients with manifest visual field defects show pathologic PhNR values, and the PhNR seems promising in detecting early glaucoma. However, distinguishing between healthy subjects and suspect patients at risk of developing glaucomatous damage still remains challenging. Thus, comparing reports of the routine examinations (optic disc assessment, OCT RNFL measurement, standard automated perimetry) with the results of electrophysiological examinations might be helpful in the differential diagnosis of uncertain clinical cases. In particular, the PhNR and the steady-state pattern ERG optimized for glaucoma screening (PERGLA) can explore the parvocellular and magnocellular pathways, respectively. The combined peculiarities of these two techniques could give ophthalmologists a useful feedback to detect early alterations suggestive of glaucomatous pathology and stratify the risk. Furthermore, the PhNR could also represent a useful additional tool in monitoring the progression of glaucomatous disease. One of the main limitations in previous studies investigating the role of PhNR in glaucoma was the lack of a standardized technique in assessing this ERG component. However, the ISCEV has now provided a way to partially overcome this issue by publishing its extended protocol for recording and analysing the PhNR.

In conclusion, we believe that the PhNR may be worthy of more clinical consideration, and further research following international guidelines and involving larger populations in longitudinal studies might gain more insight into glaucoma pathophysiology as well as early detection of disease and risk assessment.

Acknowledgements Open access funding provided by Università di Pisa within the CRUI-CARE Agreement.

Author contributions Material preparation and literature search were performed by MP. MP had the idea for the article and performed data analysis and interpretation. All authors commented on previous versions of the manuscript, revised the work and approved the final manuscript.

Funding No funding was received for this article.

Availability of data and material Not applicable.

\section{Compliance with ethical standards}

Conflicts of interest The authors declare that they have no conflicts of interest.

Ethics approval This article does not contain any studies with human participants or animals performed by any of the authors.

Consent to participate Not applicable.

Consent for publication Not applicable.

Open Access This article is licensed under a Creative Commons Attribution 4.0 International License, which permits use, sharing, adaptation, distribution and reproduction in any medium or format, as long as you give appropriate credit to the original author(s) and the source, provide a link to the Creative Commons licence, and indicate if changes were made. The images or other third party material in this article are included in the article's Creative Commons licence, unless indicated otherwise in a credit line to the material. If material is not 
included in the article's Creative Commons licence and your intended use is not permitted by statutory regulation or exceeds the permitted use, you will need to obtain permission directly from the copyright holder. To view a copy of this licence, visit http://creativecommons.org/licenses/by/4.0/.

\section{References}

1. Granit R (1933) The components of the retinal action potential in mammals and their relation to the discharge in the optic nerve. J Physiol 77:207-239

2. Penn RD, Hagins WA (1969) Signal transmission along retinal rods and the origin of the electroretinographic a-wave. Nature 223:201-204

3. Miller RF, Dowling JE (1970) Intracellular responses of the Müller (glial) cells of mudpuppy retina: their relation to b-wave of the electroretinogram. J Neurophysiol 33:323-341

4. Robson JG, Frishman LJ (1995) Response linearity and kinetics of the cat retina: the bipolar cell component of the dark-adapted electroretinogram. Vis Neurosci 12:837-850

5. Brown KT, Watanabe K (1962) Isolation and identification of a receptor potential from the pure cone fovea of the monkey retina. Nature 193:958

6. Whitten DN, Brown KT (1973) The time courses of late receptor potentials from monkey cones and rods. Vis Res 13:107-135

7. Heynen H, van Norren D (1985) Origin of the electroretinogram in the intact macaque eye-I. Principal component analysis. Vis Res 25:697-707

8. Bush RA, Sieving PA (1994) A proximal retinal component in the primate photopic ERG a-wave. Investig Ophthalmol Vis Sci 35:635-645

9. Sieving PA, Murayama K, Naarendorp F (1994) Push-pull model of the primate photopic electroretinogram: a role for hyperpolarizing neurons in shaping the b-wave. Vis Neurosci 11:519-532

10. Spileers W, Falcaoreis F, Smith R, Hogg C, Arden GB (1993) The human erg evoked by a ganzfeld stimulator powered by red and green light-emitting-diodes. Vis Res 8:21-39

11. Viswanathan S, Frishman LJ, Robson JG, Harwerth RS, Smith EL (1999) The photopic negative response of the macaque electroretinogram: reduction by experimental glaucoma. Investig Ophthalmol Vis Sci 40:1124-1136

12. Machida S (2012) Clinical applications of the photopic negative response to optic nerve and retinal diseases. J Ophthalmol 2012:397178

13. Viswanathan S, Frishman LJ, Robson JG (2000) The uniform field and pattern ERG in macaques with experimental glaucoma: removal of spiking activity. Investig Ophthalmol Vis Sci 41:2797-2810

14. Rangaswamy NV, Frishman LJ, Dorotheo EU, Schiffman JS, Bahrani HM, Tang RA (2004) Photopic ERGs in patients with optic neuropathies: comparison with primate ERGs after pharmacologic blockade of inner retina. Investig Ophthalmol Vis Sci 45:3827-3837
15. Tang J, Edwards T, Crowston JG, Sarossy M (2014) The test-retest reliability of the photopic negative response (PhNR). Transl Vis Sci Technol 3:1

16. Horn FK, Gottschalk K, Mardin CY, Pangeni G, Jünemann AG, Kremers J (2011) On and off responses of the photopic fullfield ERG in normal subjects and glaucoma patients. Doc Ophthalmol 122:53-62

17. Rosolen SG, Rigaudière F, LeGargasson JF, Chalier C, Rufiange M, Racine J, Joly S, Lachapelle P (2004) Comparing the photopic ERG i-wave in different species. Vet Ophthalmol 7:189-192

18. Viswanathan S, Frishman LJ, Robson JG, Walters JW (2001) The photopic negative response of the flash electroretinogram in primary open angle glaucoma. Investig Ophthalmol Vis Sci 42:514-522

19. Mortlock KE, Binns AM, Aldebasi YH, North RV (2010) Inter-subject, inter-ocular and inter-session repeatability of the photopic negative response of the electroretinogram recorded using DTL and skin electrodes. Doc Ophthalmol 121:123-134

20. Rangaswamy NV, Shirato S, Kaneko M, Digby BI, Robson JG, Frishman LJ (2007) Effects of spectral characteristics of ganzfeld stimuli on the photopic negative response (PhNR) of the ERG. Investig Ophthalmol Vis Sci 48:4818-4828

21. Sustar M, Cvenkel B, Brecelj J (2009) The effect of broadband and monochromatic stimuli on the photopic negative response of the electroretinogram in normal subjects and in open-angle glaucoma patients. Doc Ophthalmol 118:167-177

22. Dacey DM (1996) Circuitry for color coding in the primate retina. Proc Natl Acad Sci USA 93:582-588

23. Dacey DM, Packer OS (2003) Colour coding in the primate retina: diverse cell types and cone-specific circuitry. Curr Opin Neurobiol 13:421-427

24. DeMonasterio FM, Schein SJ, McCrane EP (1981) Staining of blue-sensitive cones of the macaque retina by a fluorescent dye. Science 213:1278-1281

25. Greenstein VC, Hood DC, Ritch R, Steinberger D, Carr RE (1989) S (blue) cone pathway vulnerability in retinitis pigmentosa, diabetes and glaucoma. Investig Ophthalmol Vis Sci 30:1732-1737

26. Yamamoto S, Kamiyama M, Nitta K, Yamada T, Hayasaka S (1996) Selective reduction of the $\mathrm{S}$ cone electroretinogram in diabetes. Br J Ophthalmol 80:973-975

27. Drasdo N, Aldebasi YH, Chiti Z, Mortlock KE, Morgan JE, North RV (2001) The s-cone PHNR and pattern ERG in primary open angle glaucoma. Investig Ophthalmol Vis Sci 42:1266-1272

28. Kremers J, Jertila M, Link B, Pangeni G, Horn FK (2012) Spectral characteristics of the PhNR in the full-field flash electroretinogram of normals and glaucoma patients. Doc Ophthalmol 124:79-90

29. Racette L, Sample PA (2003) Short-wavelength automated perimetry. Ophthalmol Clin N Am 16(227-36):vi-vii

30. North RV, Jones AL, Drasdo N, Wild JM, Morgan JE (2010) Electrophysiological evidence of early functional damage in glaucoma and ocular hypertension. Investig Ophthalmol Vis Sci 51:1216-1222

31. Stiles WS, Burch JM (1959) N.P.L. Colour-matching investigation: final report (1958). Opt Acta Int J Opt 6:1-26 
32. Rufiange M, Dumont M, Lachapelle P (2005) Modulation of the human photopic ERG luminance-response function with the use of chromatic stimuli. Vis Res 45:2321-2330

33. Frishman L, Sustar M, Kremers J, McAnany JJ, Sarossy M, Tzekov R, Viswanathan S (2018) ISCEV extended protocol for the photopic negative response (PhNR) of the full-field electroretinogram. Doc Ophthalmol 136:207-211

34. Binns AM, Mortlock KE, North RV (2011) The relationship between stimulus intensity and response amplitude for the photopic negative response of the flash electroretinogram. Doc Ophthalmol 122:39-52

35. Colotto A, Falsini B, Salgarello T, Iarossi G, Galan ME, Scullica L (2000) Photopic negative response of the human ERG: losses associated with glaucomatous damage. Investig Ophthalmol Vis Sci 41:2205-2211

36. Fortune B, Bui BV, Cull G, Wang L, Cioffi GA (2004) Interocular and inter-session reliability of the electroretinogram photopic negative response ( $\mathrm{PhNR}$ ) in non-human primates. Exp Eye Res 78:83-93

37. Wali N, Leguire LE (1992) Fundus pigmentation and the dark-adapted electroretinogram. Doc Ophthalmol 80:1-11

38. Westall CA, Dhaliwal HS, Panton CM, Sigesmun D, Levin AV, Nischal KK, Héon E (2001) Values of electroretinogram responses according to axial length. Doc Ophthalmol 102:115-130

39. Kundra H, Park JC, McAnany JJ (2016) Comparison of photopic negative response measurements in the time and time-frequency domains. Doc Ophthalmol 133:91-98

40. Van Alstine AW, Viswanathan S (2017) Test-retest reliability of the multifocal photopic negative response. Doc Ophthalmol 134:25-36

41. Joshi NR, Ly E, Viswanathan S (2017) Intensity response function of the photopic negative response ( $\mathrm{PhNR})$ : effect of age and test-retest reliability. Doc Ophthalmol 135:1-16

42. Preiser D, Lagrèze WA, Bach M, Poloschek CM (2013) Photopic negative response versus pattern electroretinogram in early glaucoma. Investig Ophthalmol Vis Sci 54:1182-1191

43. Kirkiewicz M, Lubiński W, Penkala K (2016) Photopic negative response of full-field electroretinography in patients with different stages of glaucomatous optic neuropathy. Doc Ophthalmol 132:57-65

44. Machida S, Tamada K, Oikawa T, Gotoh Y, Nishimura T, Kaneko M, Kurosaka D (2011) Comparison of photopic negative response of full-field and focal electroretinograms in detecting glaucomatous eyes. J Ophthalmol. https://doi. org/10.1155/2011/564131

45. Shen X, Huang L, Fan N, He J (2013) Relationship among photopic negative response, retinal nerve fiber layer thickness, and visual field between normal and POAG eyes. ISRN Ophthalmol 2013:182021

46. Karanjia R, Berezovsky A, Sacai PY, Cavascan NN, Liu HY, Nazarali S, Moraes-Filho MN, Anderson K, Tran JS, Watanabe SE, Moraes MN, Sadun F, DeNegri AM, Barboni P, Do Val Ferreira Ramos C, La Morgia C, Carelli V, Belfort R, Coupland SG, Salomao SR, Sadun AA (2017) The photopic negative response: an objective measure of retinal ganglion cell function in patients with Leber's hereditary optic neuropathy. Investig Ophthalmol Vis Sci 58:300-306
47. Gotoh Y, Machida S, Tazawa Y (2004) Selective loss of the photopic negative response in patients with optic nerve atrophy. Arch Ophthalmol 122:341-346

48. Kim HD, Park JY, Ohn YH (2010) Clinical applications of photopic negative response $(\mathrm{PhNR})$ for the treatment of glaucoma and diabetic retinopathy. Korean J Ophthalmol 24:89-95

49. Machida S, Gotoh Y, Tanaka M, Tazawa Y (2004) Predominant loss of the photopic negative response in central retinal artery occlusion. Am J Ophthalmol 137:938-940

50. Moss HE, Park JC, McAnany JJ (2015) The photopic negative response in idiopathic intracranial hypertension. Investig Ophthalmol Vis Sci 56:3709-3714

51. Park JC, Moss HE, McAnany JJ (2018) Electroretinography in idiopathic intracranial hypertension: comparison of the pattern ERG and the photopic negative response. Doc Ophthalmol 136:45-55

52. Banerjee A, Khurana M, Sachidanandam R, Sen P (2019) Comparison between broadband and monochromatic photopic negative response in full-field electroretinogram in controls and subjects with primary open-angle glaucoma. Doc Ophthalmol 138:21-33

53. Cvenkel B, Sustar M, Perovšek D (2017) Ganglion cell loss in early glaucoma, as assessed by photopic negative response, pattern electroretinogram, and spectral-domain optical coherence tomography. Doc Ophthalmol 135:17-28

54. Bach M, Pfeiffer N, Birkner-Binder D (1992) Patternelectroretinogram reflects diffuse retinal damage in early glaucoma. Clin Vis Sci 7:335-340

55. Bach M, Sulimma F, Gerling J (1997) Little correlation of the pattern electroretinogram (PERG) and visual field measures in early glaucoma. Doc Ophthalmol 94:253-263

56. Klistorner AI, Graham SL, Martins A (2000) Multifocal pattern electroretinogram does not demonstrate localised field defects in glaucoma. Doc Ophthalmol 100:155-165

57. Harrison WW, Viswanathan S, Malinovsky VE (2006) Multifocal pattern electroretinogram: cellular origins and clinical implications. Optom Vis Sci 83:473-485

58. Niyadurupola N, Luu CD, Nguyen DQ, Geddes K, Tan GX, Wong CC, Tran T, Coote MA, Crowston JG (2013) Intraocular pressure lowering is associated with an increase in the photopic negative response (PhNR) amplitude in glaucoma and ocular hypertensive eyes. Invest Ophthalmol Vis Sci 54:1913-1919

59. Machida S, Gotoh Y, Toba Y, Ohtaki A, Kaneko M, Kurosaka D (2008) Correlation between photopic negative response and retinal nerve fiber layer thickness and optic disc topography in glaucomatous eyes. Investig Ophthalmol Vis Sci 49:2201-2207

60. Machida S, Toba Y, Ohtaki A, Gotoh Y, Kaneko M, Kurosaka D (2008) Photopic negative response of focal electoretinograms in glaucomatous eyes. Investig Ophthalmol Vis Sci 49:5636-5644

61. Machida S, Tamada K, Oikawa T, Yokoyama D, Kaneko M, Kurosaka D (2010) Sensitivity and specificity of photopic negative response of focal electoretinogram to detect glaucomatous eyes. Br J Ophthalmol 94:202-208

62. Machida S, Kaneko M, Kurosaka D (2015) Regional variations in correlation between photopic negative response of focal electoretinograms and ganglion cell complex in glaucoma. Curr Eye Res 40:439-449 
63. Kaneko M, Machida S, Hoshi Y, Kurosaka D (2015) Alterations of photopic negative response of multifocal electroretinogram in patients with glaucoma. Curr Eye Res 40:77-86

64. Wilsey L, Gowrisankaran S, Cull G, Hardin C, Burgoyne CF, Fortune B (2017) Comparing three different modes of electroretinography in experimental glaucoma: diagnostic performance and correlation to structure. Doc Ophthalmol 134:111-128

65. Luo X, Frishman LJ (2011) Retinal pathway origins of the pattern electroretinogram (PERG). Investig Ophthalmol Vis Sci 52:8571-8584

66. Hood DC, Greenstein VC, Holopigian K, Bauer R, Firoz B, Liebmann JM, Odel JG, Ritch R (2000) An attempt to detect glaucomatous damage to the inner retina with the multifocal ERG. Investig Ophthalmol Vis Sci 41:1570-1579

67. Fortune B, Johnson CA, Cioffi GA (2001) The topographic relationship between multifocal electroretinographic and behavioral perimetric measures of function in glaucoma. Optom Vis Sci 78:206-214

68. Fortune B, Bearse MA, Cioffi GA, Johnson CA (2002) Selective loss of an oscillatory component from temporal retinal multifocal ERG responses in glaucoma. Investig Ophthalmol Vis Sci 43:2638-2647

69. Stiefelmeyer S, Neubauer AS, Berninger T, Arden GB, Rudolph G (2004) The multifocal pattern electroretinogram in glaucoma. Vis Res 44:103-112

70. Ledolter AA, Monhart M, Schoetzau A, Todorova MG, Palmowski-Wolfe AM (2015) Structural and functional changes in glaucoma: comparing the two-flash multifocal electroretinogram to optical coherence tomography and visual fields. Doc Ophthalmol 130:197-209

71. Bach M, Poloschek CM (2013) Electrophysiology and glaucoma: current status and future challenges. Cell Tissue Res 353:287-296

72. Bach M, Hoffmann MB (2008) Update on the pattern electroretinogram in glaucoma. Optom Vis Sci 85:386-395

73. Bui BV, Fortune B, Cull G, Wang L, Cioffi GA (2003) Baseline characteristics of the transient pattern electroretinogram in non-human primates: inter-ocular and inter-session variability. Exp Eye Res 77:555-566

74. Ventura LM, Porciatti V (2006) Pattern electroretinogram in glaucoma. Curr Opin Ophthalmol 17:196-202

75. Porciatti V (2015) Electrophysiological assessment of retinal ganglion cell function. Exp Eye Res 141:164-170

76. Banitt MR, Ventura LM, Feuer WJ, Savatovsky E, Luna G, Shif O, Bosse B, Porciatti V (2013) Progressive loss of retinal ganglion cell function precedes structural loss by several years in glaucoma suspects. Investig Ophthalmol Vis Sci 54:2346-2352

77. Bode SF, Jehle T, Bach M (2011) Pattern electroretinogram in glaucoma suspects: new findings from a longitudinal study. Investog Ophthalmol Vis Sci 52:4300-4306

Publisher's Note Springer Nature remains neutral with regard to jurisdictional claims in published maps and institutional affiliations. 